\title{
ASTHMA
}

\section{Use of sequential quadrupling dose regimens to study efficacy of inhaled corticosteroids in asthma}

\author{
K Phillips, J Oborne, T W Harrison, A E Tattersfield
}

Thorax 2004:59:21-25. doi: 10.1136/thx.2003.015289

See end of article for authors' affiliations

.....................

Correspondence to: Dr K Phillips, Division of Respiratory Medicine, Clinical Sciences Building, City Hospital, Nottingham NG5 1PB, UK: dr_kate_phillips@ hotmail.com

Received 26 August 2003 Accepted 2 October 2003
Background: Inhaled corticosteroids are widely used to treat asthma. There is a need to be able to compare different inhaled corticosteroids and different doses of an inhaled corticosteroid to determine potency and dose equivalence, but measuring efficacy in a dose related manner is difficult because of their slow onset of action. There is uncertainty about the role of sequential dosing regimens and the best end point for such studies. We have explored the use of sequential quadrupling dose regimens and a range of end points to assess the response to budesonide in subjects with asthma.

Methods: 21 subjects with mild asthma, aged 18-65, took part in a randomised three way crossover study comparing two sequential and one non-sequential regimen, separated by at least 3 weeks. The sequential regimens consisted of increasing doses of inhaled budesonide (100, $4001600 \mu \mathrm{g} /$ day) with each dose being given for 1 or 2 weeks; the non-sequential regimen consisted of $1600 \mu \mathrm{g} /$ day for 2 weeks with end points measured after 1 and 2 weeks. The end points studied included the provocative dose of adenosine monophosphate causing a $20 \%$ fall in forced expiratory volume in 1 second ( $\left.P D_{20} A M P\right)$, lung function, symptoms, and bronchodilator use.

Results: There was a dose related increase in $\mathrm{PD}_{20} \mathrm{AMP}$ with both sequential dose regimens. The increase in $\mathrm{PD}_{20} \mathrm{AMP}$ ranged from 1.49 doubling doses (DD) following the lowest dose (100 $\mu \mathrm{g} /$ day) to $3.1 \mathrm{DD}$ following the highest dose $(1600 \mu \mathrm{g} /$ day $)$ in the 1 week sequential regimen and from 1.98 to 4.03 DD in the 2 week sequential regimen; standard deviations (SD) for the changes in $\mathrm{PD}_{20} \mathrm{AMP}$ ranged from 1.3 to 2.6 DD. Changes in forced expiratory volume in 1 second $\left(\mathrm{FEV}_{1}\right)$ and morning peak expiratory flow rate (PEFR) were dose related but small and more variable (maximum change in $\mathrm{FEV}_{1}=148 \mathrm{ml}$, SD $228 \mathrm{ml}$ ), while changes in evening PEFR, symptoms, and bronchodilator use were small and not dose related. Change in $\mathrm{PD}_{20} \mathrm{AMP}$ after budesonide $1600 \mu \mathrm{g}$ did not differ significantly between regimens.

Conclusion: Combining $\mathrm{PD}_{20} \mathrm{AMP}$ measurements with a sequential regimen of three quadrupling doses of an inhaled corticosteroid given for 1 or 2 weeks provides clear dose-response curves for comparative studies. $\mathrm{PD}_{20} \mathrm{AMP}$ is a more sensitive end point for this purpose than $F E V_{1}, P E F R$, symptoms, or relief inhaler use. nhaled corticosteroids are a very effective treatment for asthma. There are marked differences in the pharmacokinetic profiles of the inhaled corticosteroids currently available, $^{12}$ and these are likely to affect their systemic activity relative to their therapeutic airway effects. It is important to be able to compare the efficacy and adverse effects of different inhaled corticosteroids and different doses of an inhaled corticosteroid to determine their potency and dose equivalence.

Comparing the efficacy of two drugs should ideally involve a dose-response comparison but, because the response to an inhaled corticosteroid continues to improve for weeks or months after starting treatment, ${ }^{3-6}$ such studies are difficult. There is uncertainty about the optimal end point to use for such studies and whether sequential dosing regimens can overcome some of the problems. This study was therefore designed to explore the use of sequential dosing regimens in conjunction with various commonly used outcome measures.

We compared the magnitude and variability of change in bronchial responsiveness to adenosine monophosphate (AMP), forced expiratory volume in 1 second $\left(\mathrm{FEV}_{1}\right)$, morning and evening peak expiratory flow rate (PEFR), symptoms, and bronchodilator use following two sequential quadrupling dose regimens with doses of budesonide increasing at 1 and 2 week intervals. Change in the provocative dose of AMP causing a $20 \%$ fall in $\mathrm{FEV}_{1}$ $\left(\mathrm{PD}_{20} \mathrm{AMP}\right)$ following the $1600 \mu \mathrm{g}$ dose of budesonide was compared between the two sequential regimens and between these regimens and the first and second week, respectively, of the non-sequential regimen.

\section{METHODS \\ Subjects}

Subjects were included in the study if they were aged 18-65 years, had a diagnosis of asthma, symptoms consistent with asthma, and bronchial hyperresponsiveness to AMP $\left(\mathrm{PD}_{20} \mathrm{AMP}<29.5 \mu \mathrm{M}\right.$ at screening). Subjects were excluded if the $\mathrm{FEV}_{1}$ was less than $60 \%$ predicted or if they were a current smoker or had a smoking history of more than 10 pack years. Those taking asthma medication other than an inhaled short acting $\beta$ agonist as required or sodium cromoglycate were excluded as were those who had taken an inhaled steroid in the previous 4 weeks or oral steroids in the previous 3 months or had had an exacerbation or chest infection within 6 weeks. Women of child bearing age had to be using adequate contraception.

The study was approved by the Nottingham City Hospital research ethics committee and subjects gave written informed consent.

\section{Measurements}

$\mathrm{FEV}_{1}$ was measured by dry bellows spirometer (Vitalograph, Buckingham, UK) as the larger of two values within $100 \mathrm{ml}$. The provocative dose of adenosine monophosphate causing a 
$20 \%$ fall in $\mathrm{FEV}_{1}\left(\mathrm{PD}_{20} \mathrm{AMP}\right)$ was determined using a breath activated dosimeter (MEFAR, Brescia, Italy) set to nebulise for 1 second with a pause of 6 seconds at a pressure of $152 \mathrm{kPa}$. Adenosine monophosphate (Sigma, UK) was dissolved in $0.9 \%$ saline to give a doubling dose range from 0.115 to $472 \mu \mathrm{M}$. An initial inhalation of $0.9 \%$ saline was followed by doubling doses of AMP with $\mathrm{FEV}_{1}$ measured 2 minutes after each dose. The inhalation challenge was stopped once $\mathrm{FEV}_{1}$ had fallen by $20 \%$ from the post-saline value or the maximum dose of AMP had been inhaled. $\mathrm{PD}_{20}$ values were calculated by interpolation between the last two doses on the log dose-response scale; censored values above $472 \mu \mathrm{M}$ were arbitrarily assigned double the maximum dose $(944 \mu \mathrm{M})$ while a response to the initial saline inhalation was assigned the minimum dose $(0.115 \mu \mathrm{M})$. Subjects kept diary cards, recording peak flow rate as the highest of three attempts (mini-Wright peak flow meter), symptoms, and use of relief inhaler twice daily. All subjects received training in spirometric testing and AMP challenge before entry into the study.

\section{Study protocol}

The study had a single blind crossover design in which patients took sequentially increasing doses of inhaled budesonide for 1 or 2 weeks or a course of high dose budesonide for 2 weeks. The doses given were as follows:

- budesonide 100, 400 and $1600 \mu \mathrm{g} /$ day for 1 week each;

- budesonide 100, 400 and $1600 \mu \mathrm{g} /$ day for 2 weeks each;

- budesonide $1600 \mu \mathrm{g} /$ day for 2 weeks.

The doses were divided and given twice daily apart from the $100 \mu \mathrm{g}$ dose which had to be given once daily as there is no $50 \mu \mathrm{g}$ Turbohaler; previous studies have shown no difference in efficacy between once and twice daily low dose budesonide. $^{78}$ The three regimens were given in random order determined independently by computer generated code. There was a washout period of at least 3 weeks following each dosing regimen.

Subjects were taught to use the inhalers at the first visit. They were given four inhalers containing active drug or placebo at the start of each dose period, two labelled for morning use and two for evening use, and all were returned at the end of each dose period.

Subjects attended at the beginning of each treatment period and then weekly during the l week sequential regimen and the non-sequential regimen and 2 weekly during the 2 week sequential regimen; all visits were at the same time of day within 2 hours. At each visit diary cards were checked and use of medication confirmed followed by spirometric tests and an AMP challenge. Subjects were asked to withhold their inhaled $\beta$ agonist for 6 hours before each visit and caffeine-containing food and drink from midnight. The main purpose of the study was to determine the magnitude and variability of change in $\mathrm{PD}_{20} \mathrm{AMP}, \mathrm{FEV}_{1}$, peak flow rate, symptoms, and relief inhaler use in the two sequential regimens. We also set out to compare changes in $\mathrm{PD}_{20} \mathrm{AMP}$ after $1600 \mu \mathrm{g}$ budesonide with all three regimens.

\section{Analysis of data}

$\mathrm{PD}_{20}$ values were log transformed before analysis and geometric mean values calculated; change in $\mathrm{PD}_{20} \mathrm{AMP}$ was measured in doubling doses. The percentage of days and nights without symptoms and use of relief inhaler and mean morning and evening PEFR were calculated for the 7 days before each visit. Maximum change in $\mathrm{PD}_{20} \mathrm{AMP}$ and $\mathrm{FEV}_{1}$ were analysed for period effects by two way analysis of variance (ANOVA). Mean dose-response slopes were calculated for the sequential regimens after fitting regression slopes for each end point against the log dose for each subject. Changes in $\mathrm{PD}_{20} \mathrm{AMP}$ after $1600 \mu \mathrm{g}$ budesonide in the 1 and 2 week sequential dose regimens were compared with each other and with changes in $\mathrm{PD}_{20} \mathrm{AMP}$ after the first and second week, respectively, of the $1600 \mu \mathrm{g}$ non-sequential regimen by paired $t$ test.

\section{RESULTS}

Of 24 subjects randomised, two were excluded before study entry due to failure to attend and failure to bronchoconstrict with AMP; a third subject was withdrawn after one treatment period due to worsening asthma. Twenty one subjects were included in the analysis, one of whom

\begin{tabular}{|c|c|c|c|c|}
\hline Sex & Age & $\begin{array}{l}\text { Baseline FEV } \\
\text { (\% predicted) }\end{array}$ & Reversibility $(\%) \dagger$ & $\mathrm{PD}_{20} \mathrm{AMP}(\mu \mathrm{M})$ \\
\hline $\mathrm{F}$ & 46 & 67 & 36 & 2.75 \\
\hline M & 44 & 77 & 36 & 0.23 \\
\hline M & 48 & 88 & 6 & 11.94 \\
\hline $\mathrm{F}$ & 36 & 98 & 6 & 0.92 \\
\hline M & 31 & 87 & 19 & 12.50 \\
\hline M & 59 & 78 & 11 & 14.70 \\
\hline M & 41 & 64 & 28 & 0.12 \\
\hline M & 50 & 70 & 15 & 17.00 \\
\hline M & 42 & 79 & 8 & 20.79 \\
\hline $\mathrm{F}$ & 45 & 86 & 9 & 10.42 \\
\hline M & 48 & 108 & 12 & 14.70 \\
\hline M & 33 & 84 & 12 & 23.55 \\
\hline M & 54 & 67 & 27 & 14.45 \\
\hline M & 22 & 88 & 8 & 11.56 \\
\hline $\mathrm{F}$ & 41 & 77 & 21 & 0.80 \\
\hline $\mathrm{F}$ & 41 & 73 & 14 & 1.27 \\
\hline M & 62 & 63 & 14 & 0.26 \\
\hline M & 34 & 102 & 1 & 24.96 \\
\hline $\mathrm{F}$ & 31 & 86 & 17 & 2.28 \\
\hline $\mathrm{F}$ & 44 & 110 & 5 & 6.13 \\
\hline F & 30 & 84 & 13 & 2.47 \\
\hline Mean values & 42 & 83 & 15 & $4.10^{*}$ \\
\hline
\end{tabular}


completed two treatment periods but failed to develop a $\mathrm{PD}_{20} \mathrm{AMP}$ at the start of the third. All but five of 227 potential $\mathrm{PD}_{20}$ AMP data points were available for analysis. Of the 17 $\mathrm{PD}_{20}$ measurements that were censored to $944 \mu \mathrm{M} 16$ were associated with the highest dose of budesonide and these were evenly distributed throughout the three treatment regimens.

The 21 subjects ( 13 men) had a mean age of 42 years; baseline demographic data are shown in table 1 . There was no period effect for maximum change in $\mathrm{PD}_{20} \mathrm{AMP}$ or $\mathrm{FEV}_{1}$.

\section{Dose-response changes with budesonide $\mathrm{PD}_{20} \mathrm{AMP}$}

There was a dose related increase in $\mathrm{PD}_{20} \mathrm{AMP}$ with both sequential regimens. The change in $\mathrm{PD}_{20} \mathrm{AMP}$ ranged from 1.49 doubling doses (DD) following the lowest dose ( $100 \mu \mathrm{g} /$ day) to $3.1 \mathrm{DD}$ following the highest dose ( $1600 \mu \mathrm{g} / \mathrm{day})$ for the 1 week regimen and from 1.98 DD to $4.03 \mathrm{DD}$ for the 2 week regimen. The standard deviation of the measurements ranged from 1.3 DD to 2.6 DD AMP (fig 1, table 2). The dose-response relationship for budesonide was significant for both sequential regimens. The mean slope of change in $\mathrm{PD}_{20} \mathrm{AMP}$ was $1.43(95 \% \mathrm{CI} 0.64$ to 2.22$) \mathrm{DD}$ per quadrupling dose of budesonide for the weekly regimen and 1.73 (95\% CI 0.72 to 2.74$)$ DD doses for the 2 weekly regimen.

\section{Lung function}

There was a small dose related increase in $\mathrm{FEV}_{1}$ which was significant for the 1 week but not for the 2 week sequential regimen. The size of the response ranged from $-14 \mathrm{ml}$ following the lowest dose to $90 \mathrm{ml}$ following the highest dose in the 1 week sequential regimen and from $50 \mathrm{ml}$ to $148 \mathrm{ml}$ in the 2 week sequential regimen (fig 2, table 2). The variability of the response was large with standard deviations ranging from 192 to $367 \mathrm{ml}$.

Morning PEFR also showed a small dose related increase which was significant for the 1 week but not the 2 week regimen (fig 3, table 2). Mean absolute values for the lowest to highest doses of budesonide ranged from 470 to 491 l/min for the 1 week regimen and from 469 to $484 \mathrm{l} / \mathrm{min}$ for the 2 week sequential regimen; the standard deviation of the measurements was around $90 \mathrm{l} / \mathrm{min}$. Changes in evening PEFR were small and not dose related (fig 3).

\section{Symptoms and bronchodilator use}

There were no dose related effects of treatment on daytime or night time symptoms or bronchodilator use with either sequential regimen (table 2 ).

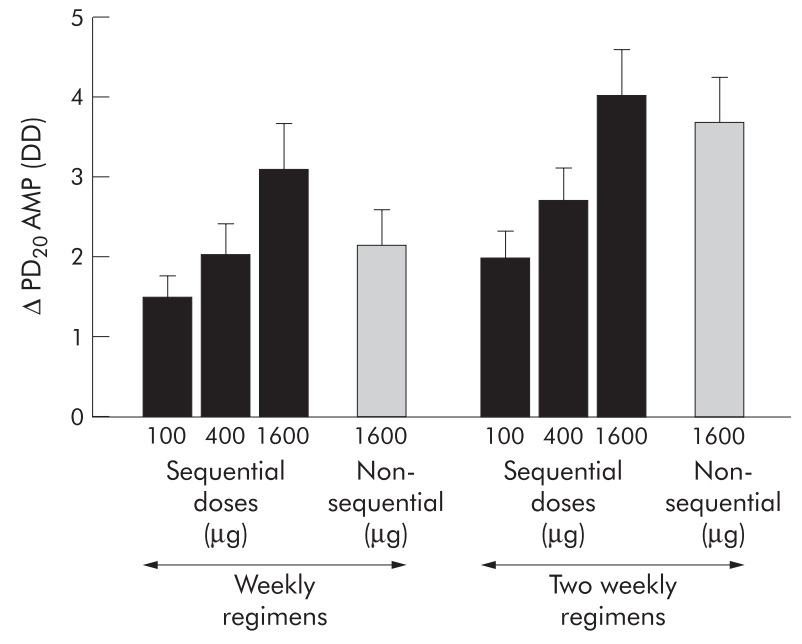

Figure 1 Mean (SE) change in $\mathrm{PD}_{20} \mathrm{AMP}$ (doubling doses, DD) after quadrupling doses of budesonide in the 1 and 2 week sequential regimens and after the first and second week of $1600 \mu \mathrm{g}$ in the nonsequential regimen.

\section{Maximum change in $\mathrm{PD}_{20} \mathrm{AMP}$ with each regimen}

The change in $\mathrm{PD}_{20} \mathrm{AMP}$ following $1600 \mu \mathrm{g}$ budesonide was higher with the 2 week regimen than with the l week sequential regimen although the difference was not significant (fig 1). The change in $\mathrm{PD}_{20} \mathrm{AMP}$ with $1600 \mu \mathrm{g}$ budesonide was also higher with the sequential than with the non-sequential regimen after both 1 week $(0.75 \mathrm{DD})$ and 2 weeks (0.4 DD), but again neither difference was significant (table 3).

\section{DISCUSSION}

In this crossover study in patients with mild asthma there was a large dose related increase in $\mathrm{PD}_{20} \mathrm{AMP}$ following three sequential quadrupling doses of budesonide with both the 1 and 2 week regimens. Changes in $\mathrm{FEV}_{1}$ and morning PEFR were small and less clear cut than $\mathrm{PD}_{20} \mathrm{AMP}$ and were only dose related in the 1 week regimen; changes in evening PEFR, symptoms, and relief inhaler use were small and were not dose related.

Previous dose-response studies of inhaled corticosteroids have sometimes shown dose related changes but not always, due in part to differences in study design and end points measured..$^{9-15}$ We therefore compared two sequential dosing regimens and a range of end points to assess the response to an inhaled corticosteroid. Sequential dosing regimens may

Table 2 Mean (SD) change in $\mathrm{PD}_{20} \mathrm{AMP}, \mathrm{FEV}_{1}$, and morning and evening PEFR and median (interquartile range) days and nights free of symptoms and bronchodilator use for all three dosing regimens

\begin{tabular}{|c|c|c|c|c|c|c|c|c|}
\hline & \multicolumn{3}{|c|}{1 week sequential regimen } & \multicolumn{3}{|c|}{2 week sequential regimen } & \multicolumn{2}{|c|}{ Non-sequential regimen } \\
\hline & $100 \mu \mathrm{g}$ & $400 \mu \mathrm{g}$ & $1600 \mu \mathrm{g}$ & $100 \mu \mathrm{g}$ & $400 \mu \mathrm{g}$ & $1600 \mu \mathrm{g}$ & $\begin{array}{l}1600 \mu \mathrm{g} \\
1 \text { week }\end{array}$ & $\begin{array}{l}1600 \mu \mathrm{g} \\
2 \text { weeks }\end{array}$ \\
\hline$\triangle \mathrm{PD}_{20} \mathrm{AMP}(\mathrm{DD})$ & $1.49(1.30)$ & $2.04(1.74)$ & $3.10(2.53)$ & $1.96(1.53)$ & $2.71(1.80)$ & $4.03(2.51)$ & $2.14(1.99)$ & $3.70(2.60)$ \\
\hline$\triangle \mathrm{FEV}_{1}(\mathrm{ml})$ & $-14(192)$ & $77(226)$ & $90(243)$ & $50(367)$ & $124(242)$ & $148(228)$ & $113(250)$ & $81(252)$ \\
\hline am PEFR (I/min) & $470(88.3)$ & $483(83.3)$ & $490(87.5)$ & $483(89.2)$ & $483(91.8)$ & $483(92.8)$ & $484(94.4)$ & 488 (88.9) \\
\hline pm PEFR (I/min) & $480(91.5)$ & $478(93.9)$ & 489 (89.7) & $487(91.6)$ & 481 (94.2) & $480(96.5)$ & $480(92.7)$ & $490(89.2)$ \\
\hline $\begin{array}{l}\text { Symptom free } \\
\text { nights (\%) }\end{array}$ & $100(71-100)$ & $100(86-100)$ & $100(100-100)$ & $100(71-100)$ & $100(79-100)$ & $100(86-100)$ & $100(77-100)$ & $100(100-100)$ \\
\hline $\begin{array}{l}\text { Symptom free } \\
\text { days (\%) }\end{array}$ & $100(64-100)$ & $100(64-100)$ & $100(69-100)$ & $100(54-100)$ & $100(74-100)$ & $100(84-100)$ & $86(60-100)$ & $100(57-100)$ \\
\hline $\mathrm{BD}$ free nights (\%) & $100(100-100)$ & $100(100-100)$ & $100(100-100)$ & 100 (89-100) & $100(100-100)$ & $100(100-100)$ & $100(86100)$ & $100(100-100)$ \\
\hline $\mathrm{BD}$ free days (\%) & $100(71-100)$ & $100(93-100)$ & $100(77-100)$ & 100 (39-100) & $100(81-100)$ & $100(83-100)$ & $100(69-100)$ & $100(85-100)$ \\
\hline
\end{tabular}

$\mathrm{DD}=$ doubling doses; $\mathrm{FEV}_{1}=$ forced expiratory volume in 1 second; $\mathrm{PD}_{20} \mathrm{AMP}=$ provocative dose of adenosine monophosphate causing a $20 \%$ fall in $\mathrm{FEV} \mathrm{V}_{1}$; $\mathrm{PEFR}=$ peak expiratory flow rate; $\mathrm{BD}=$ bronchodilator. 


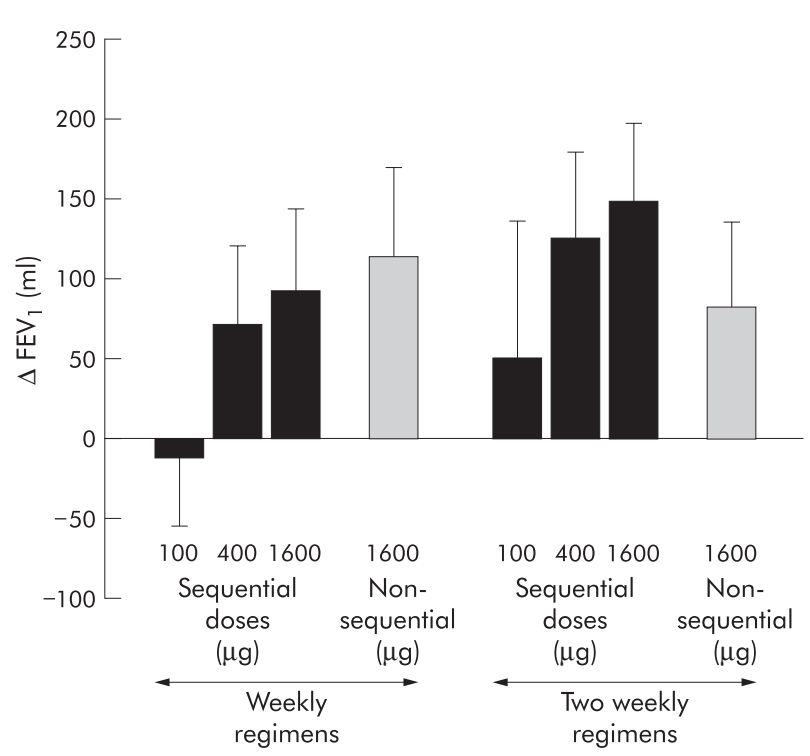

Figure 2 Mean (SE) change in $\mathrm{FEV}_{1}$ after quadrupling doses of budesonide in the 1 and 2 week sequential regimens and after the first and second week of $1600 \mu \mathrm{g}$ in the non-sequential regimen.

offer advantages when comparing different inhaled corticosteroids and different doses of an inhaled corticosteroid. They are shorter than traditional crossover studies which require a washout period after each dose, and they require fewer subjects than parallel group studies.
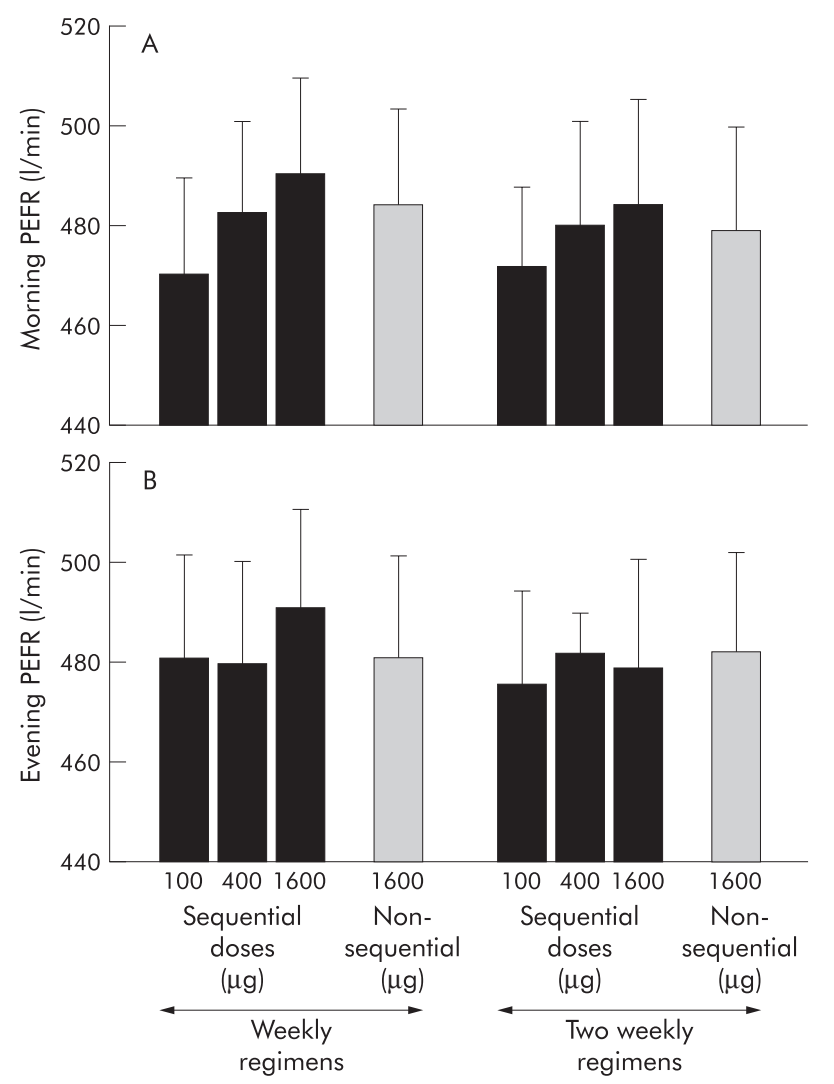

Figure 3 Mean (SE) morning (A) and evening (B) peak expiratory flow rates (PEFR) after quadrupling doses of budesonide in the 1 week and 2 week sequential regimens and after the first and second week of $1600 \mu \mathrm{g}$ in the non-sequential regimen.
Table 3 Mean $(95 \% \mathrm{Cl})$ difference in change in $\mathrm{PD}_{20} \mathrm{AMP}$ after $1600 \mu \mathrm{g}$ budesonide between the two sequential regimens and between the sequential and nonsequential regimens

\begin{tabular}{lll}
\hline $\begin{array}{l}\text { Regimens being } \\
\text { compared }\end{array}$ & $\begin{array}{l}\text { Difference in change in } \\
\text { PD }_{20} \mathbf{A M P}^{*}\end{array}$ & p value \\
\hline $\begin{array}{l}\text { Sequential } \\
\quad 1 \text { week } v 2 \text { weeks }\end{array}$ & $0.95(-0.55$ to 2.44$)$ & 0.20 \\
$\begin{array}{l}\text { Sequential } v \text { non-sequential } \\
\quad 1 \text { week }\end{array}$ & $0.75(-0.48$ to 1.97$)$ & 0.22 \\
2 weeks & $0.40(-0.98$ to 1.79$)$ & 0.55 \\
\hline *Mean difference in doubling doses with $95 \% \mathrm{Cl}$. & \\
\hline
\end{tabular}

By using quadrupling doses of an inhaled corticosteroid we found a large dose related increase in $\mathrm{PD}_{20} \mathrm{AMP}$ even in subjects with mild asthma. The variability in the response was small in relation to the size of change in $\mathrm{PD}_{20} \mathrm{AMP}$ and similar for the two sequential regimens, suggesting that moderate numbers of subjects would be required for comparative studies. The mean effect of treatment on bronchial responsiveness is probably an underestimate since treatment with budesonide caused a small number of $\mathrm{PD}_{20} \mathrm{AMP}$ values to be censored, although these were evenly distributed between treatment regimens. Bronchial responsiveness to AMP was a more sensitive end point than measures of lung function, symptoms, and relief inhaler use and would appear to have considerable advantages for comparative and dose-response studies of inhaled corticosteroids. The poor sensitivity of the other end points was partly caused by the fact that we studied subjects with mild asthma; however, these subjects have other advantages for studies of inhaled corticosteroids since they are less likely to require other medication or to have an exacerbation during the study. Bronchial responsiveness appears to correlate well with more clinical markers of efficacy as detailed in the companion paper also published in this issue of Thorax. ${ }^{16}$

Three previous studies have used sequential doubling dose regimens to compare systemic and airway effects of inhaled corticosteroids. ${ }^{13-15}$ The largest changes were seen in the study that measured $\mathrm{PC}_{20} \mathrm{AMP}$ following $1600 \mu \mathrm{g}$ budesonide after doubling increments every 3 weeks, ${ }^{14}$ and the size of the effect was similar to that seen in our study. Use of quadrupling doses with shorter treatment periods, as in our study, should enable the duration of dose-response comparisons to be reduced.

The changes in $\mathrm{PD}_{20} \mathrm{AMP}$ seen with sequential dosing regimens will relate to duration of treatment as well as dose. This appeared to be the case since, although not significant individually, the changes in $\mathrm{PD}_{20} \mathrm{AMP}$ following $1600 \mu \mathrm{g}$ budesonide were greater after 2 weeks than after 1 week, both within and between the sequential and non-sequential regimens.

We conclude that combining measurement of $\mathrm{PD}_{20} \mathrm{AMP}$ with a sequential quadrupling dose regimen in which doses are increased at 1 or 2 week intervals provides a simple and efficient method to assess the response to an inhaled corticosteroid. This should facilitate comparisons of different inhaled corticosteroids and different doses of an inhaled corticosteroid.

\section{ACKNOWLEDGEMENTS}

The authors thank AstraZeneca for providing financial support and indistinguishable active and placebo inhalers, Sarah Pacey for subject randomisation and dispensing the medication, Sarah Lewis for statistical advice, and Sarah Newton and Sue Cooper for help with the subjects. 


\section{Authors' affiliations}

K Phillips, J Oborne, T W Harrison, A E Tattersfield, Division of Respiratory Medicine, University of Nottingham, City Hospital, Nottingham NG5 1PB, UK

\section{REFERENCES}

1 Johnson M. Pharmacodynamics and pharmacokinetics of inhaled glucocorticoids. J Allergy Clin Immunol 1996;97:169-76.

2 Harrison TW. Systemic availability of inhaled budesonide and fluticasone propionate. Biodrugs 2001;15:405-11.

3 Vathenen AS, Knox AJ Wisniewski A, et al Time course of change in bronchial reactivity with an inhaled corticosteroid in asthma. Am Rev Respir Dis 1991;143:1317-21

4 Kraan J, Koëter GH, Van Der Mark ThW, et al. Dosage and time effects of inhaled budesonide on bronchial hyperreactivity. Am Rev Respir Dis 1988;137:44-8.

5 Haahtela $T$, Järvinen $M$, Kava T. Comparison of a $\beta_{2}$-agonist, terbutaline, with an inhaled corticosteroid, budesonide, in newly detected asthma. NEngl J Med 1991;325:388-92.

6 Juniper EF, Kline PA, Vanzieleghem MA, et al. Effect of long term treatmen with an inhaled corticosteroid (budesonide) on airway hyperresponsiveness and clinical asthma in nonsteroid-dependent asthmatics. Am Rev Respir Dis 1990; 142:832-6.

7 Chisholm SL, Dekker FW, Knuistingh Neven A, et al. Once-daily budesonide in mild asthma. Respir Med 1998:92:421-5.

8 Jónasson G, Carlsen K-H, Blomqvist P. Clinical efficacy of low-dose inhaled budesonide once or twice daily in children with mild asthma not previously treated with steroids. Eur Respir J 1998;12:1099-104.
9 Taylor DA, Jensen MW, Kanabar V, et al. A dose dependent effect of the novel inhaled corticosteroid ciclesonide on airway responsiveness to adenosine-5'-monophosphate in asthmatic patients. Am J Respir Crit Care Med 1999; 160:237-43.

10 Shapiro G, Bronsky EA, LaForce CF, et al. Dose-related efficacy of budesonide administered via a dry powder inhaler in the treatment of children with moderate to severe persistent asthma. J Paediatr 1998;132:976-82.

11 Noonan MJ, Chervinsky P, Wolfe J, et al. Dose-related response to inhaled fluticasone propionate in patients with methacholine induced bronchial hyperresponsiveness: a double blind, placebo controlled study. J Asthma 1998;35:153-64.

12 Busse WW, Chervinsky P, Condemi J, et al. Budesonide delivered by Turbuhaler is effective in a dose-dependent fashion when used in the treatment of adult patients with chronic asthma. J Allergy Clin Immunol 1998;101:457-63.

13 Nielsen LP, Dahl R. Therapeutic ratio of inhaled corticosteroids in adult asthma. A dose-range comparison between fluticasone propionate and budesonide, measuring their effect on bronchial hyperresponsiveness and adrenal cortex function. Am J Respir Crit Care Med 2000; 162:2053-7.

14 Wilson AM Lipworth BJ. Dose-response evaluation of the therapeutic index for inhaled budesonide in patients with mild to moderate asthma. Am J Med 2000;108:269-75.

15 McCubbin MM, Milavetz G, Grandgeorge S, et al. A bioassay for topical and systemic effect of three inhaled corticosteroids. Clin Pharmacol Ther 1995; 57:455-60.

16 Phillips K, Oborne J, Lewis S, et al. Time course of action of two inhaled corticosteroids, fluticasone propionate and budesonide. Thorax 2004;59:26-30

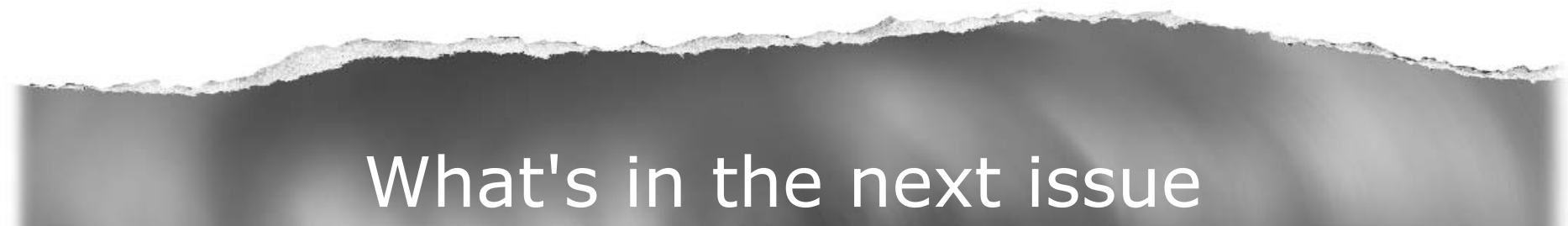

\section{Future content}

See which articles have just been accepted for publication and preview the table of contents for the next issue a month before it is published

www.thoraxjnl.com 